\title{
Landscape Connectivity Limits the Predicted Impact of Fungal Pathogen Invasion
}

\author{
Zhimin Li ${ }^{1}{ }^{\circledR}$, An Martel ${ }^{1}$, Sergé Bogaerts ${ }^{2}$, Bayram Göçmen ${ }^{3,+}{ }^{\dagger}$ Panayiotis Pafilis ${ }^{4}$, \\ Petros Lymberakis ${ }^{5}{ }^{(D}$, Tonnie Woeltjes ${ }^{6}$, Michael Veith ${ }^{7}$ and Frank Pasmans ${ }^{1, *}$ \\ 1 Wildlife Health Ghent, Faculty of Veterinary Medicine, Ghent University, Salisburylaan 133, \\ B9820 Merelbeke, Belgium; Zhimin.li@ugent.be (Z.L.); an.martel@ugent.be (A.M.) \\ 2 Lupinelaan 25, NL5582 CG Aalst, The Netherlands; s-bogaerts@hetnet.nl \\ 3 Faculty of Science, Department of Biology, Zoology Section, Ege University, TR-35100 İzmir, Turkey \\ 4 Department of Zoology and Marine Biology, School of Biology, National and Kapodistrian University of \\ Athens, Panepistimioupolis, Ilissia, 15784 Athens, Greece; ppafil@biol.uoa.gr \\ 5 Natural History Museum of Crete, School of Sciences and Engineering, University of Crete, Knossos Ave., \\ 1409 Irakleio, Greece; lyberis@nhmc.uoc.gr \\ 6 Molenweg 43, 6542PR Nijmegen, The Netherlands; a.woeltjes7@upcmail.nl \\ 7 Department of Biogeography, Trier University, Universitätsring 15, D-54296 Trier, Germany; \\ veith@uni-trier.de \\ * Correspondence: frank.pasmans@ugent.be \\ + Decease.
}

Received: 3 September 2020; Accepted: 30 September 2020; Published: 3 October 2020

\begin{abstract}
Infectious diseases are major drivers of biodiversity loss. The risk of fungal diseases to the survival of threatened animals in nature is determined by a complex interplay between host, pathogen and environment. We here predict the risk of invasion of populations of threatened Mediterranean salamanders of the genus Lyciasalamandra by the pathogenic chytrid fungus Batrachochytrium salamandrivorans by combining field sampling and lab trials. In 494 samples across all seven species of Lyciasalamandra, B. salamandrivorans was found to be absent. Single exposure to a low (1000) number of fungal zoospores resulted in fast buildup of lethal infections in three L. helverseni. Thermal preference of the salamanders was well within the thermal envelope of the pathogen and body temperatures never exceeded the fungus' thermal critical maximum, limiting the salamanders' defense opportunities. The relatively low thermal host preference largely invalidates macroclimatic based habitat suitability predictions and, combined with current pathogen absence and high host densities, suggests a high probability of local salamander population declines upon invasion by B. salamandrivorans. However, the unfavorable landscape that shaped intraspecific host genetic diversity, lack of known alternative hosts and rapid host mortality after infection present barriers to further, natural pathogen dispersal between populations and thus species extinction. The risk of anthropogenic spread stresses the importance of biosecurity in amphibian habitats.
\end{abstract}

Keywords: Batrachochytrium salamandrivorans; salamander; Lyciasalamandra; thermal ecology; susceptibility

\section{Introduction}

With half of all extant species of salamanders and newts (urodeles) estimated to be threatened or extinct, this amphibian order is among the globally most threatened vertebrate taxa (Global Amphibian Assessment, 2008). The recent incursion of the chytrid fungus Batrachochytrium salamandrivorans in Europe added a threat to the survival of most western Palearctic urodele taxa [1]. B. salamandrivorans induced urodele die offs now have been diagnosed in four European species in four countries. Invasion 
of B. salamandrivorans in populations of endangered, small range endemics may lead to species extinction [2]. Predicting the impact of B. salamandrivorans invasion in threatened urodele communities is key to guiding conservation priorities and is often based on macroclimate niche modeling and/or experimental infections [3-8]. Neglecting host dependence on specific microclimatic conditions may, however, confound such risk analyses.

The eastern Mediterranean is characterized by a remarkable diversity of highly specialized, terrestrial salamanders of the genus Lyciasalamandra. This genus contains 7 species and 20 subspecies, all of which are threatened according to International Union for Conservation of Nature (IUCN). Most of these (sub-) species occupy small ranges and are restricted to habitats that provide access to underground, relatively cool and humid conditions year round. This allows them to escape the arid and hot summer conditions [9,10], but also unfavorable weather conditions during the winter [11]. Surface activity of these salamanders is restricted to cool and wet weather and at least for coastal populations, most activity is between November and April [12]. Their close relatedness to salamanders that are considered highly vulnerable to B. salamandrivorans-induced disease (European fire salamanders, Salamandra salamandra; further: fire salamander), low reproductive output (females typically give birth to two fully developed offspring once a year), relatively low life expectancy $[11,13,14]$ and small distribution ranges could prompt conclusions that Lyciasalamandra species are highly vulnerable to severe, infectious disease driven declines and even extinction. The extent of the impact would, however, also be determined by pathogen transmission success between salamander populations and by host thermal ecology. B. salamandrivorans has been shown to spread slowly [15], and natural (non-anthropogenic) spread is associated with the presence of pathogen carriers $[2,16,17]$. Salamander body temperatures that exceed the lethal temperatures of $25^{\circ} \mathrm{C}$ for $B$. salamandrivorans could suppress or even eliminate infection $[18,19]$. We here predict the risk $B$. salamandrivorans poses to the survival of the genus Lyciasalamandra by combining a susceptibility lab trial with a B. salamandrivorans prevalence study in the species' range and collecting lab and field data on the host species' thermal ecology.

\section{Materials and Methods}

\subsection{Infection Dynamics of B. Salamandrivorans in Lyciasalamandra Helverseni}

We compared infection dynamics of B. salamandrivorans between Lyciasalamandra helverseni and the reference urodele species for susceptibility: the fire salamander (Salamandra salamandra). Permits were obtained to transfer Lyciasalamandra helverseni from the Greek island of Karpathos to captivity (149621/3441/28-12-2016). For conservation reasons, an absolute minimum of three replicates was used, which should suffice in case the animals show an infection pattern broadly similar to that of the well-studied fire salamanders. Three captive, subadult $L$. helverseni and three captive bred, subadult fire salamanders were inoculated with $10^{3}$ zoospores of the B. salamandrivorans type strain AMFP1 using an established protocol [1]. Briefly, animals were individually exposed for $24 \mathrm{~h}$ at $15^{\circ} \mathrm{C}$ to $10^{3}$ zoospores of $B$. salamandrivorans in $1 \mathrm{~mL}$ of water. Afterwards, the salamanders were housed individually in plastic containers, lined with moist tissue and containing a polyvinyl chloride (PVC) pipe as a hiding place. Temperatures were kept constant at $15^{\circ} \mathrm{C}$ and dim, natural light was provided. The salamanders were fed two times weekly ad libitum with crickets (Acheta domestica). Infection loads were followed up by weekly sampling of all animals using cotton tipped swabs and subsequent qPCR analysis to quantify B. salamandrivorans loads [20]. The experiment was approved by the ethical committee of Ghent University (2017/75) on October 30th, 2017.

\subsection{B. Salamandrivorans Prevalence in Populations of the Genus Lyciasalamandra}

Across the range of all 7 species of Lyciasalamandra (Figure 1), skin swabs were collected during the surface activity period of the salamanders in Turkey (winter, spring of 2013) and on the Greek islands of Kasos and Karpathos (March 2017). Animals were found resting under stones during daytime or were found active at the surface at night. Animals were caught by hand. For each animal, a new 
pair of disposable vinyl gloves was used. Animals were released on site immediately after sampling. A minimum of 30 specimens per Lyciasalamandra species was envisaged. This allows the detection of a B. salamandrivorans prevalence of at least $10 \%$ with $95 \%$ confidence. To obtain a Bayesian $95 \%$ credible interval for prevalence, the R2WinBUGS package and WinBUGS were used to estimate the posterior distribution of prevalence following the description of previous studies [21,22]. We used a uniform prior probability distribution for prevalence estimates (e.g., prevalence $\mathrm{U}$ ). Three parallel Markov chains with 20,000 iterations each were run, discarding the first 5000 iterations as the burn-in. Chains were not thinned.

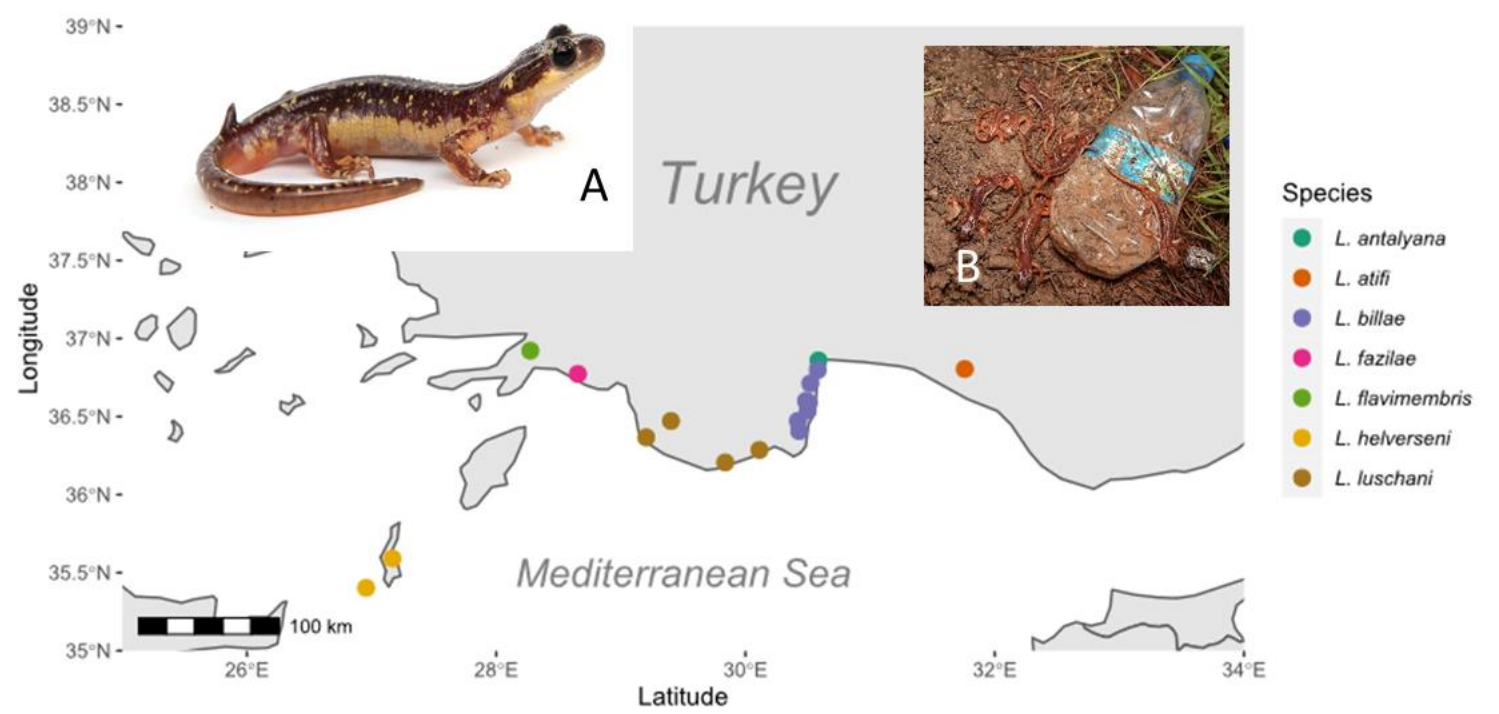

Figure 1. Sampling locations of the 7 Lyciasalamandra species in Turkey and the Greek islands of Karpathos and Kasos. The inserts show an adult male Lyciasalamandra helverseni (A) and communal use by L. billae of a hiding place in an anthropogenically disturbed habitat (B).

\subsection{Thermal Ecology of Lyciasalamandra Sp}

We here assessed to what extent the Lyciasalamandra body temperatures overlap with the B. salamandrivorans thermal envelope (spanning $5{ }^{\circ} \mathrm{C}-20{ }^{\circ} \mathrm{C},[23]$ ). We collected two sets of field data to estimate Lyciasalamandra body temperatures. A first set of data consisted of opportunistically collected data of Turkish populations during the species' period of surface activity (winter and spring) from 1996-2020 (Supplementary Table S1). During March 2017, temperature data were collected from a larger sample of $L$. helverseni from Kassos and Karpathos. Temperatures were measured at a maximum distance of $30 \mathrm{~cm}$ using an infrared thermometer (Fluke 561). To determine thermal preference of $L$. helverseni, 10 salamanders were placed in a thermal gradient container $(80 \mathrm{~cm} \times 19 \mathrm{~cm})$ with temperatures ranging between $5{ }^{\circ} \mathrm{C}-35^{\circ} \mathrm{C}$ on moist tissue, with extensive access to shelters across the thermal range. Salamanders were housed in groups of 3 or 4 animals and left to acclimate for 2 days before the onset of measurements. Body temperatures were measured during the following 3 days using the infrared thermometer pointed at midbody, at a distance of less than $5 \mathrm{~cm}$ from the animal. At least 6 temperature readings per animal were recorded.

Statistics were performed using SPSS version 25 (SPSS Inc., Chicago, IL, USA), by performing a non-parametric one-way ANOVA analysis on the temperature, with significance set to $p<0.05$.

\subsection{Thermal Environment of B. Salamandrivorans in Lyciasalamandra Habitats}

Since B. salamandrivorans poorly tolerates elevated temperatures and is eliminated from urodele hosts within 10 days (Blooi et al., 2015), the host thermal environment may facilitate predicting the risk and impact of $B$. salamandrivorans invasion. The seasonal temperature variation at 15 Turkish Lyciasalamandra sites, comprising 6 species (Supplementary Table S3), was recorded using Tinytag 
Dataloggers (Gemini Data Loggers UK Ltd., Chichester, UK.) between February 1997 and February 1999. For comparison between sites, we recorded the local temperature under big rocks (typical daytime shelters during surface activity); measurements were taken at the respective end of three-hour intervals throughout almost one year per site and logger. In addition, at some sites we also studied potential salamander hiding places (within stone walls, mammal holes, leaf litter and boulder fields) in order to see how temperature variations are buffered within underground shelters. To account for the thermal critical maximum of $25^{\circ} \mathrm{C}$ of B. salamandrivorans [23], we counted the number of days with a temperature exceeding $25^{\circ} \mathrm{C}$ and the number and longest period of days where the temperature did not drop below $25^{\circ} \mathrm{C}$.

\section{Results}

\subsection{Lyciasalamandra Helverseni Quickly Develops Lethal Infection Loads of B. Salamandrivorans}

Experimental infection of $L$. helverseni resulted in rapid increase in B. salamandrivorans loads (average of $\log$ (10) genomic equivalents (GE): $4.32+/-0.31$ (standard deviation)) and humane end points for euthanasia (lethargy, skin lesions, abnormal postures) were reached at 4 weeks post exposure in all three animals. Infection dynamics and disease course were highly comparable to those observed in the reference fire salamanders (Figure 2).
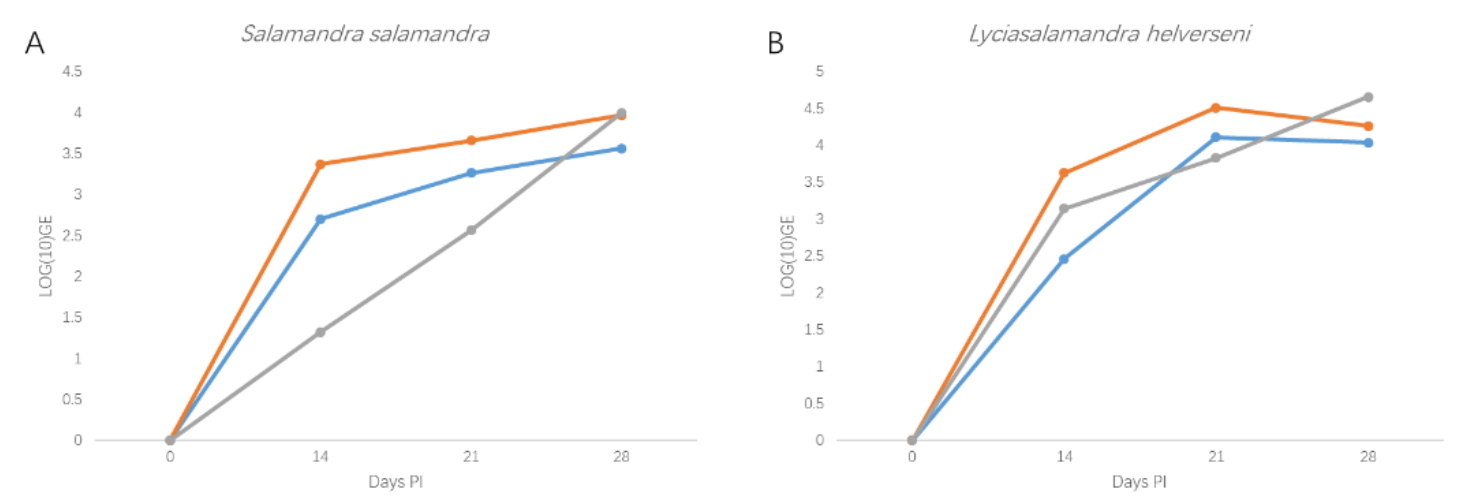

Figure 2. Infection dynamics in S. salamandra (A) and L. helverseni (B) after experimental exposure to B. salamandrivorans. Infection loads are shown as $\log (10)$ GE values. Each line represents a single animal.

\subsection{B. Salamandrivorans Is Absent from Natural Populations of Lyciasalamandra sp}

In total, 494 samples of Lyciasalamandra species across the entire genus range were found negative for B. salamandrivorans (Table 1). For each species, at least 30 samples were examined (Supplementary Table S2).

Table 1. All seven species of Lyciasalamandra populations were sampled for B. salamandrivorans presence, the last column indicates the Bayesian 95\% credible intervals.

\begin{tabular}{cccc}
\hline Species & Sample Size & B. Salamandrivorans Prevalence & (Bayesian 95\% Credible Interval) \\
\hline L. atifi & 30 & 0.00 & $(0.00,0.11)$ \\
\hline L. antalyana & 30 & 0.00 & $(0.00,0.11)$ \\
\hline L. billae & 97 & 0.00 & $(0.00,0.04)$ \\
\hline L. luschani & 121 & 0.00 & $(0.00,0.03)$ \\
\hline L. fazilae & 30 & 0.00 & $(0.00,0.11)$ \\
\hline L. flavimembris & 30 & 0.00 & $(0.00,0.11)$ \\
\hline L. helverseni & 156 & 0.00 & $(0.00,0.03)$ \\
total & 494 & 0.00 & $(0.00,0.01)$ \\
\hline
\end{tabular}




\subsection{Lyciasalamandra Body Temperatures Fit the B. Salamandrivorans Thermal Envelope}

All temperatures measured during salamander surface activity in the field and in the lab trial are well below the thermal critical maximum of $25^{\circ} \mathrm{C}$ of B. salamandrivorans [23]. The opportunistic sampling of Turkish specimens yielded 19 measurements from five species. Animals in hiding places had an average body temperature of $12.8^{\circ} \mathrm{C}$ (range: $8.4^{\circ} \mathrm{C}-16.4{ }^{\circ} \mathrm{C}, n=12$ ) and active animals $10.6^{\circ} \mathrm{C}$ (range: $6{ }^{\circ} \mathrm{C}-14.2{ }^{\circ} \mathrm{C}, n=7$ ). For the Greek L. helverseni, average body temperatures were $10.5^{\circ} \mathrm{C}$ (range: $3.8^{\circ} \mathrm{C}-14.6{ }^{\circ} \mathrm{C}, n=35$ ) in hiding places and $8.2^{\circ} \mathrm{C}$ (range: $4.6^{\circ} \mathrm{C}-12.8^{\circ} \mathrm{C}, n=75$ ) when active (Supplementary Figure S1).

L. helverseni housed in a thermal gradient had an average body temperature of $16.3{ }^{\circ} \mathrm{C}+/-0.6{ }^{\circ} \mathrm{C}$ (standard error of the mean (SEM)). A marked group effect ( $p \leq 0.001$ ) was noticed, and average temperatures per group were $13.5{ }^{\circ} \mathrm{C}, 17.1{ }^{\circ} \mathrm{C}$ and $18.0{ }^{\circ} \mathrm{C}$. Of 68 temperature measurements, body temperature exceeded $20^{\circ} \mathrm{C}$ on three occasions, and the highest temperature recorded during the experiment was $20.5^{\circ} \mathrm{C}$.

The temperature loggers placed in the field in 15 Turkish populations yielded consistent results during the salamanders' surface activity period (November-April; Figure 3, Supplementary Table S3).
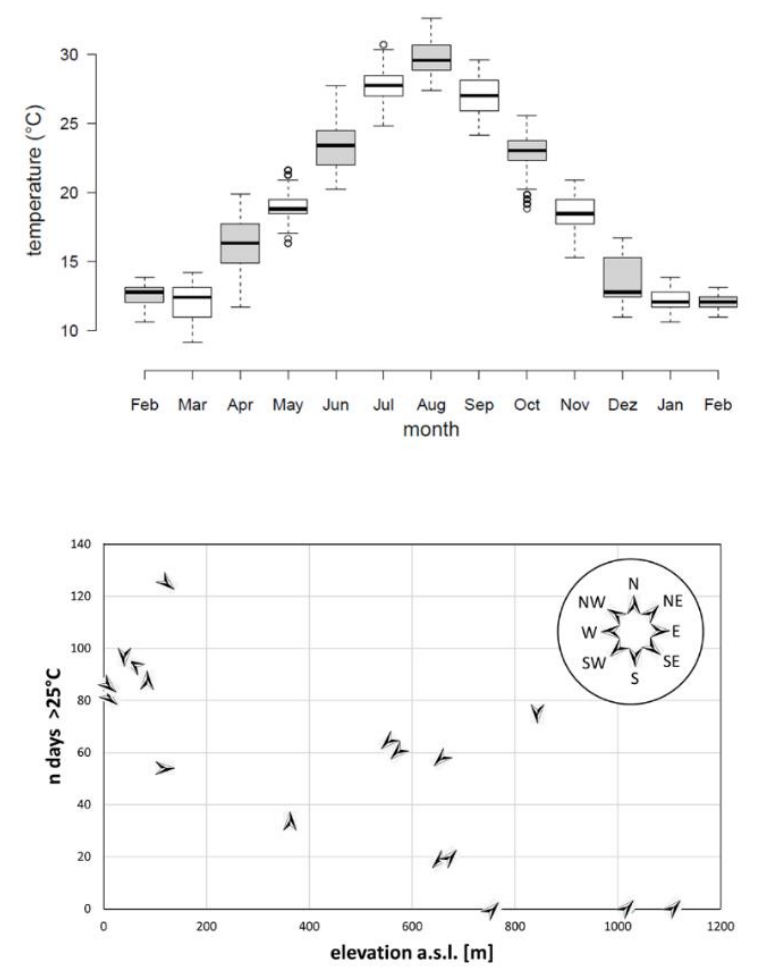

Figure 3. Year round temperature recordings in 15 Lyciasalamandra habitats. The upper panel shows box plots of temperature recordings in an alleged salamander hiding place under a stone in a representative coastal population of L. billae as an example of seasonal fluctuations in a population where most surface activity is between November and April. The lower panel shows the number of days on which the recorded temperature exceeded $25^{\circ} \mathrm{C}$ in alleged salamander hiding places in relation to altitude. Temperatures were recorded year-round in 15 populations belonging to 6 Turkish Lyciasalamandra species. Arrows indicate the orientation of the slope, defined as the compass direction that the slope faces toward.

\subsection{Thermal Conduciveness of Lyciasalamandra Surface Habitats for B. Salamandrivorans Survival}

On average, 2858 readings were collected per temperature logging device. Temperatures in alleged salamander hiding places varied year-round between $-0.1^{\circ} \mathrm{C}-41.3^{\circ} \mathrm{C}$, with an overall average temperature of $17.5^{\circ} \mathrm{C}\left(\mathrm{SEM} 0.6^{\circ} \mathrm{C}\right)$. When considering a constant temperature of at least $25^{\circ} \mathrm{C}$ over at 
least 10 days lethal for $B$. salamandrivorans, temperature readings at 12 sites suggested poor year-round fungal survival at the site of recording. In contrast, three sites at higher elevation did not yield a single day with temperatures exceeding $25^{\circ} \mathrm{C}$ (Figure 3).

\section{Discussion}

Combined results from lab trials and field data suggest that invasion of B. salamandrivorans poses a threat to Lyciasalamandra species at population level, with expected declines as witnessed in fire salamanders across Europe [23]. Animals succumbed quickly after experimental infection with a single, relatively low dose of $B$. salamandrivorans, in line with the disease outcome observed in their sister genus Salamandra [1]. Within population transmission is highly likely, given the high population densities of Lyciasalamandra species [10], frequent communal use of hiding places [24] and courtship behavior that involves intimate contact (amplexus, [25]). Whether infection and disease dynamics during a natural outbreak would follow a similar scenario to those in fire salamanders remains unclear. The rapid decline and extirpation observed in the latter have been associated with the presence of pathogen reservoirs, which at least partly explains why the epidemiology does not follow a density dependent pattern [17]. With multiple, highly transmitting hosts in the community, transmission increases, resulting in a higher possibility of a severe outbreak [26]. Known pathogen reservoirs include co-occurring amphibian hosts that are persistently and often subclinically infected [17]. Although at least some anurans may be B. salamandrivorans carriers, natural infections in frogs and toads so far have been observed in eastern Asian species [27], and are very rare in anurans of European amphibian communities invaded by B. salamandrivorans $[1,28]$. Furthermore, the surface of the karstic limestone habitats inhabited by the salamanders is not home to a significant anuran community. If the lack of other urodele species and the scarcity of anuran hosts in the Lyciasalamandra range would imply absence of suitable pathogen reservoirs, infection and disease dynamics can be expected to be density dependent [26,29], rendering population extirpation less likely. However, current knowledge does not allow the exclusion of the presence of non-amphibian pathogen reservoirs, which may be biotic (for example invertebrate pathogen reservoirs as proposed for $B$. dendrobatidis $[30,31]$ or abiotic (long term survival of resistant fungal spores). Abiotic reservoirs should maintain sufficient humidity levels and suitable temperatures for B. salamandrivorans to survive. B. salamandrivorans infection was shown to be transmitted through contaminated soil [17]. B. salamandrivorans DNA was demonstrated up to one month in contaminated soil, incubated at $15^{\circ} \mathrm{C}$, where the fungus can remain infective for at least $48 \mathrm{~h}$. B. salamandrivorans persistence in superficial soil layers is likely during the humid season only. Our thermal recordings within the salamander habitats showed that, for the majority of sites, B. salamandrivorans is unlikely to survive the hot Mediterranean summers in the superficial soil layers in most habitats. In the absence of alternative hosts, desiccation of the few habitats that did fall within the B. salamandrivorans thermal envelope year-round can be expected to equally limit fungal survival in superficial soil layers. However, at greater depths in the karstic limestone underground, the presumed summer refugia of Lyciasalamandra, the consistently lower temperatures would offer suitable conditions for year round fungal survival. Given the comparable thermal niches of both Lyciasalamandra sp. and B. salamandrivorans, a persistently contaminated subterranean environment could markedly exacerbate the disease impact and may result in mass mortality events that go unnoticed.

Observations regarding thermal biology of the Mediterranean salamander genus Lyciasalamandra suggest a clear preference for temperatures below $20^{\circ} \mathrm{C}$. A similar preference for relatively low body temperatures has been observed in other Mediterranean urodele species inhabiting similar macroclimates [32-37]. This may be an important mechanism for survival of Mediterranean salamanders, since cooler temperatures coincide with refugia that provide sufficient humidity to survive the hot and dry summer. The predominantly karstic limestone region inhabited by Lyciasalamandra provides such conditions in the deeper karstic underground system. The overlap between thermal behavior of the host species and the thermal niche of the pathogen would favor growth of the latter, with the potential to cause disease and death in the host in nature, despite inhabiting superficially 
(for the fungus) unfavorable habitats. Predictions of suitability based on macroclimatic data and surface characteristics in such cases poorly represent, and in this case underestimate, the potential invasive range given extensive buffering of the salamanders' niche from macroclimatic conditions. Any predictive niche modeling of infectious diseases in ectothermic hosts should therefore focus on microclimatic conditions that take host ecology into account [18].

At species level, B. salamandrivorans can be expected to be less likely to cause extinction. Extinction would be a function of extirpation at the population level, combined with successful pathogen transmission to neighboring host populations. The genus Lyciasalamandra is characterized by marked genetic differentiation even at a very small local scale $[10,38]$. Although a limited number of contact zones between some of these lineages do exist, the generally inhospitable landscape that shaped this genetic diversity can be expected to result in poor connectivity and marked landscape resistance against the Lyciasalamandra host dispersal. Assuming that salamanders of the genus Lyciasalamandra are the only significant hosts present, this may heavily impact the epidemiology of the infection, since dispersal of B. salamandrivorans has been associated predominantly with dispersal of infected hosts [15]. Ironically, rapid mortality post infection further limits pathogen spread through infected hosts. This would mean that incursion by B. salamandrivorans is likely to affect any of the Lyciasalamandra species across their entire range only in the case of human intervention.

We therefore propose that B. salamandrivorans could pose a significant threat to the survival of any of the Lyciasalamandra taxa only in the case of multiple, independent introduction events or in the case of anthropogenic spread. Currently, introduction routes of B. salamandrivorans can only be speculated about, but human activities are held responsible for its arrival and expansion in Europe [1,39]. A recent case in Spain at over $1000 \mathrm{~km}$ of the index outbreak was linked to the release of infected, captive urodeles [2]. Since Lyciasalamandra are strictly terrestrial, introduction of B. salamandrivorans through natural vectors like waterfowl [17] is unlikely. The highly diverse populations of Lyciasalamandra combined with the presence of excellent and extensive tourist infrastructure attract a specific crowd of (often foreign, European) tourists and scientists who often visit several populations in a short timeframe. Since fomites have been suggested to play a role in introduction and spread of the pathogen [40-43] we emphasize the importance of biosecurity during activities in urodele habitats. Handling animals should be done using disposable gloves and the use of containers to temporarily house animals should be avoided. Any materials that may come in contact with the salamanders or their environment, including footwear, should be thoroughly cleaned and disinfected before visiting a different population.

In conclusion, B. salamandrivorans introduction is likely to result in local population declines of Lyciasalamandra species that may go unnoticed in the deep limestone underground, however, with a low probability of whole range spread and species extinction if further anthropogenic spread can be prevented.

Supplementary Materials: The following are available online at http://www.mdpi.com/2309-608X/6/4/205/s1, Supplementary Figure S1: Dot plot of the body temperature of L. helverseni in ${ }^{\circ} \mathrm{C}$ measured in the field, Supplementary Table S1: Body temperature of six species of Lyciasalamandra measured in the field, Supplementary Table S2: All (sub)species of Lyciasalamandra populations sampled for B. salamandrivorans presence, the last column indicates the Bayesian 95\% credible intervals, Supplementary Table S3: Recorded temperature of 6 Lyciasalamandra species from 1997 to 1999.

Author Contributions: Conceptualization, F.P., A.M. and M.V.; methodology, Z.L., F.P., A.M. and M.V.; analysis, Z.L., F.P., M.V., A.M. and S.B.; investigation, all authors; resources, F.P., A.M., M.V., B.G., S.B. and T.W.; data curation, F.P. and M.V.; writing — original draft preparation, Z.L. and F.P.; writing-review and editing, all authors; visualization, Z.L., F.P. and M.V.; supervision, F.P., M.V., P.L. and P.P.; project administration, F.P., M.V., P.L., P.P., A.M. and B.G.; funding acquisition, F.P., A.M. and M.V. All authors have read and agreed to the published version of the manuscript.

Funding: Zhimin Li was supported by the China Scholarship Council (CSC, 201707650012) and Ghent University Special Research Fund (BOF 17/CHN/018).

Acknowledgments: We thank Dino Protopapas for his valuable support in the field on Karpathos. Olaf Godmann assisted in collecting temperature readings and swab samples in the field. Andreas Kiefer kindly assisted in the field. 
Conflicts of Interest: The authors declare no conflict of interest.

\section{References}

1. Martel, A.; Blooi, M.; Adriaensen, C.; Van Rooij, P.; Beukema, W.; Fisher, M.C.; Farrer, R.A.; Schmidt, B.R.; Tobler, U.; Goka, K. Recent introduction of a chytrid fungus endangers western palearctic salamanders. Science 2014, 346, 630-631. [CrossRef] [PubMed]

2. Martel, A.; Vila-Escale, M.; Fernández-Giberteau, D.; Martinez-Silvestre, A.; Canessa, S.; Van Praet, S.; Pannon, P.; Chiers, K.; Ferran, A.; Kelly, M. Integral chain management of wildlife diseases. Conserv. Lett. 2020, e12707. [CrossRef]

3. Spitzen-van der Sluijs, A.; Martel, A.; Asselberghs, J.; Bales, E.K.; Beukema, W.; Bletz, M.C.; Dalbeck, L.; Goverse, E.; Kerres, A.; Kinet, T. Expanding distribution of lethal amphibian fungus Batrachochytrium salamandrivorans in Europe. Emerg. Infect. Dis. 2016, 22, 1286-1288. [CrossRef] [PubMed]

4. $\quad$ Richgels, K.L.; Russell, R.E.; Adams, M.J.; White, C.L.; Grant, E.H.C. Spatial variation in risk and consequence of Batrachochytrium salamandrivorans introduction in the USA. Roy. Soc. Open Sci. 2016, 3, 150616. [CrossRef]

5. Basanta, M.D.; Rebollar, E.A.; Parra-Olea, G. Potential risk of Batrachochytrium salamandrivorans in Mexico. PLOS ONE 2019, 14, e0211960. [CrossRef]

6. Yap, T.A.; Nguyen, N.T.; Serr, M.; Shepack, A.; Vredenburg, V.T. Batrachochytrium salamandrivorans and the risk of a second amphibian pandemic. Ecohealth 2017, 14, 851-864. [CrossRef]

7. Beukema, W.; Martel, A.; Nguyen, T.T.; Goka, K.; Schmeller, D.S.; Yuan, Z.; Laking, A.E.; Nguyen, T.Q.; Lin, C.F.; Shelton, J. Environmental context and differences between native and invasive observed niches of Batrachochytrium salamandrivorans affect invasion risk assessments in the western palaearctic. Divers. Distrib. 2018, 24, 1788-1801. [CrossRef]

8. Feldmeier, S.; Schefczyk, L.; Wagner, N.; Heinemann, G.; Veith, M.; Lötters, S. Exploring the distribution of the spreading lethal salamander chytrid fungus in its invasive range in Europe-a macroecological approach. PLoS ONE 2016, 11, e0165682. [CrossRef]

9. Kaya, U.; Üzüm, N.; Kumlutaş, Y.; Avci, A.; Kaska, Y.; Öz, M.; Tunç, R.; Başkale, E. Overview of conservation and red list of Turkey's threatened amphibians. FrogLog 2012, 101, 30-31.

10. Veith, M.; Baran, İ.; Godmann, O.; Kiefer, A.; Öz, M.; Tunç, M.R. A revision of population designation and geographic distribution of the Lycian salamander Mertensiella luschani (Steindachner, 1891). Zool. Middle East 2001, 22, 67-82. [CrossRef]

11. Sinsch, U.; Böcking, H.; Leskovar, C.; Öz, M.; Veith, M. Demography and lifetime growth patterns in viviparous salamanders (genus Lyciasalamandra): Living underground attenuates interspecific variation. Zool. Anz. 2017, 269, 48-56. [CrossRef]

12. Polat, F.; Başkale, E. Phenology and factors influencing the abundance of Lyciasalamandra fazilae (Amphibia: Salamandridae) in Turkey. Salamandra 2018, 54, 123-131.

13. Olgun, K.; Miaud, C.; Gautier, P. Age, growth, and survivorship in the viviparous salamander Mertensiella luschani from southwestern Turkey. Can. J. Zool. 2001, 79, 1559-1567. [CrossRef]

14. Üzüm, N.; Avcý, A.; Özcan, Ç.G.; Olgun, K. Comparison of the age structure, body size, and some growth parameters of two insular populations of Lysiasalamandra fazilae from southwestern Turkey. Russ. J. Herpetol. 2020, 27. [CrossRef]

15. Spitzen-van der Sluijs, A.; Stegen, G.; Bogaerts, S.; Canessa, S.; Steinfartz, S.; Janssen, N.; Bosman, W.; Pasmans, F.; Martel, A. Post-epizootic salamander persistence in a disease-free refugium suggests poor dispersal ability of Batrachochytrium salamandrivorans. Sci. Rep. 2018, 8, 1-8. [CrossRef] [PubMed]

16. EFSA Panel on AHAW; More, S.; Angel Miranda, M.; Bicout, D.; Bøtner, A.; Butterworth, A.; Calistri, P.; Depner, K.; Edwards, S.; Garin-Bastuji, B.; et al. Risk of survival, establishment and spread of Batrachochytrium salamandrivorans (Bsal) in the EU. EFSA J. 2018, 16, e05259. [CrossRef]

17. Stegen, G.; Pasmans, F.; Schmidt, B.R.; Rouffaer, L.O.; Van Praet, S.; Schaub, M.; Canessa, S.; Laudelout, A.; Kinet, T.; Adriaensen, C. Drivers of salamander extirpation mediated by Batrachochytrium salamandrivorans. Nature 2017, 544, 353-356. [CrossRef]

18. Beukema, W.; Pasmans, F.; Van Praet, S.; Ferri-Yáñez, F.; Kelly, M.; Laking, A.; Erens, J.; Speybroeck, J.; Verheyen, K.; Lens, L.; et al. Suppression of amphibian thermal behaviour in the wild predisposes to disease-driven population declines. Ecol. Lett.. in press. 
19. Blooi, M.; Martel, A.; Haesebrouck, F.; Vercammen, F.; Bonte, D.; Pasmans, F. Treatment of urodelans based on temperature dependent infection dynamics of Batrachochytrium salamandrivorans. Sci. Rep. 2015, 5, 8037. [CrossRef]

20. Blooi, M.; Pasmans, F.; Longcore, J.E.; Spitzen-van der Sluijs, A.; Vercammen, F.; Martel, A. Duplex real-time PCR for rapid simultaneous detection of Batrachochytrium dendrobatidis and Batrachochytrium salamandrivorans in Amphibian samples. J. Clin. Microbiol. 2013, 51, 4173-4177. [CrossRef]

21. Göçmen, B.; Veith, M.; Iğci, N.; Akman, B.; Godmann, O.; Wagner, N. No detection of the amphibian pathogen Batrachochytrium dendrobatidis in terrestrial Turkish salamanders (Lyciasalamandra) despite its occurrence in syntopic frogs (Pelophylax bedriagae). Salamandra 2013, 49, 51-55.

22. Lötters, S.; Kielgast, J.; Sztatecsny, M.; Wagner, N.; Schulte, U.; Werner, P.; Rödder, D.; Dambach, J.; Reissner, T.; Hochkirch, A. Absence of infection with the amphibian chytrid fungus in the terrestrial Alpine salamander, Salamandra atra. Salamandra 2012, 48, 58-62.

23. Martel, A.; Spitzen-van der Sluijs, A.; Blooi, M.; Bert, W.; Ducatelle, R.; Fisher, M.C.; Woeltjes, A.; Bosman, W.; Chiers, K.; Bossuyt, F.; et al. Batrachochytrium salamandrivorans sp. nov. causes lethal chytridiomycosis in amphibians. Proc. Natl. Acad. Sci. USA 2013, 110, 15325-15329. [CrossRef] [PubMed]

24. Gautier, P.; Olgun, K.; Uzum, N.; Miaud, C. Gregarious behaviour in a salamander: Attraction to conspecific chemical cues in burrow choice. Behav. Ecol. Sociobiol. 2006, 59, 836-841. [CrossRef]

25. Kieren, S.; Sparreboom, M.; Hochkirch, A.; Veith, M. A biogeographic and ecological perspective to the evolution of reproductive behaviour in the family Salamandridae. Mol. Phylogenetics Evol. 2018, 121, 98-109. [CrossRef]

26. Canessa, S.; Bozzuto, C.; Pasmans, F.; Martel, A. Quantifying the burden of managing wildlife diseases in multiple host species. Conserv. Biol. 2019, 33, 1131-1140. [CrossRef]

27. Nguyen, T.T.; Van Nguyen, T.; Ziegler, T.; Pasmans, F.; Martel, A. Trade in wild anurans vectors the urodelan pathogen Batrachochytrium salamandrivorans into Europe. Amphib-Reptilia 2017, 38, 554-556. [CrossRef]

28. Schulz, V.; Schulz, A.; Klamke, M.; Preissler, K.; Sabino-Pinto, J.; Müsken, M.; Schlüpmann, M.; Heldt, L.; Kamprad, F.; Enss, J.; et al. Batrachochytrium salamandrivorans in the Ruhr District, Germany: History, distribution, decline dynamics and disease symptoms of the salamander plague. Salamandra 2020, 56, 189-214.

29. Briggs, C.J.; Knapp, R.A.; Vredenburg, V.T. Enzootic and epizootic dynamics of the chytrid fungal pathogen of amphibians. Proc. Natl. Acad. Sci. USA 2010, 107, 9695-9700. [CrossRef]

30. McMahon, T.A.; Brannelly, L.A.; Chatfield, M.W.; Johnson, P.T.; Joseph, M.B.; McKenzie, V.J.; Richards-Zawacki, C.L.; Venesky, M.D.; Rohr, J.R. Chytrid fungus Batrachochytrium dendrobatidis has nonamphibian hosts and releases chemicals that cause pathology in the absence of infection. Proc. Natl. Acad. Sci. USA 2013, 110, 210-215. [CrossRef]

31. Oficialdegui, F.J.; Sánchez, M.I.; Monsalve-Carcaño, C.; Boyero, L.; Bosch, J. The invasive red swamp crayfish (Procambarus clarkii) increases infection of the amphibian chytrid fungus (Batrachochytrium dendrobatidis). Biol. Invasions 2019, 21, 3221-3231. [CrossRef]

32. Degani, G. Temperature tolerance in three populations of salamanders, Salamandra salamandra (L.). Br. J. Herpetol. 1982, 6, 186-187.

33. Strickland, J.C.; Pinheiro, A.P.; Cecala, K.K.; Dorcas, M.E. Relationship between behavioral thermoregulation and physiological function in larval stream salamanders. J. Herpetol. 2016, 50, 239-244. [CrossRef]

34. Lunghi, E.; Manenti, R.; Canciani, G.; Scarì, G.; Pennati, R.; Ficetola, G.F. Thermal equilibrium and temperature differences among body regions in European plethodontid salamanders. J. Therm. Biol. 2016, 60, 79-85. [CrossRef] [PubMed]

35. Feder, M.E. Thermal ecology of neotropical lungless salamanders (Amphibia: Plethodontidae): Environmental temperatures and behavioral responses. Ecology 1982, 63, 1665-1674. [CrossRef]

36. Homyack, J.A.; Haas, C.A.; Hopkins, W.A. Energetics of surface-active terrestrial salamanders in experimentally harvested forest. J. Wildl. Manag. 2011, 75, 1267-1278. [CrossRef]

37. Degani, G. Temperature selection in Salamandra salamandra (L.) larvae and juveniles from different habitats. Behav. Biol. (Paris) 1984, 9, 175-183.

38. Veith, M.; Göçmen, B.; Sotiropoulos, K.; Eleftherakos, K.; Lötters, S.; Godmann, O.; Karış, M.; Oğuz, A.; Ehl, S. Phylogeographic analyses point to long-term survival on the spot in micro-endemic Lycian salamanders. PLoS ONE 2020, 15, e0226326. [CrossRef] 
39. Hyde, K.D.; Al-Hatmi, A.M.; Andersen, B.; Boekhout, T.; Buzina, W.; Dawson, T.L.; Eastwood, D.C.; Jones, E.G.; de Hoog, S.; Kang, Y. The world's ten most feared fungi. Fungal Divers. 2018, 93, 161-194. [CrossRef]

40. European Food Safety Authority (EFSA); Balàž, V.; Gortázar Schmidt, C.; Murray, K.; Carnesecchi, E.; Garcia, A.; Gervelmeyer, A.; Martino, L.; Munoz Guajardo, I.; Verdonck, F. Scientific and technical assistance concerning the survival, establishment and spread of Batrachochytrium salamandrivorans (Bsal) in the EU. EFSA J. 2017, 15, e04739.

41. Kraay, A.N.M.; Hayashi, M.A.L.; Hernandez-Ceron, N.; Spicknall, I.H.; Eisenberg, M.C.; Meza, R.; Eisenberg, J.N.S. Fomite-mediated transmission as a sufficient pathway: A comparative analysis across three viral pathogens. BMC Infect. Dis. 2018, 18, 540. [CrossRef] [PubMed]

42. Fitzpatrick, L.D.; Pasmans, F.; Martel, A.; Cunningham, A.A. Epidemiological tracing of Batrachochytrium salamandrivorans identifies widespread infection and associated mortalities in private amphibian collections. Sci. Rep. 2018, 8, 13845. [CrossRef] [PubMed]

43. Grant, E.H.C.; Muths, E.L.; Katz, R.A.; Canessa, S.; Schmidt, B. Salamander Chytrid Fungus (Batrachochytrium salamandrivorans) in the United States-Developing Research, Monitoring, and Management Strategies; USGS OFR. 2015. Available online: https://www.researchgate.net/publication/291330968_Salamander_ Chytrid_Fungus_Batrachochytrium_salamandrivorans_in_the_United_States_-Developing_Research_ Monitoring_and_Management_Strategies (accessed on 15 September 2020). [CrossRef]

(C) 2020 by the authors. Licensee MDPI, Basel, Switzerland. This article is an open access article distributed under the terms and conditions of the Creative Commons Attribution (CC BY) license (http://creativecommons.org/licenses/by/4.0/). 